\title{
Percepções sobre presença social em interações mediadas por dispositivos de
} comunicação móveis

\section{José Bonifácio do Amparo Sobrinho}

Doutorando; Universidade Federal da Bahia, Salvador, BA, Brasil jbonifacioamso@gmail.com

\section{Marcel Ayres}

Doutorando; Universidade Federal da Bahia, Salvador, BA, Brasil marcel.ayres@gmail.com

\section{José Carlos Ribeiro}

Doutor; Universidade Federal da Bahia, Salvador, BA, Brasil jcsr01@gmail.com

\section{Resumo}

Este artigo apresenta uma análise qualitativa sobre a percepção da Presença Social em interações mediadas por dispositivos móveis, tomando como foco principal de exploração as particularidades associadas à ausência ou diminuição de pistas não verbais (habitualmente ocorridas nesta modalidade de mediação). Os dados são provenientes de uma pesquisa realizada com 120 jovens universitários de seis cidades brasileiras. Os relatos dos respondentes apontaram, em geral, dificuldades na percepção da presença social devido à sobreposição de demandas e expectativas sociais derivadas de duas modalidades interacionais: via dispositivos móveis e face a face.

\section{Palavras-chave}

Presença social. Interações sociais. Interações mediadas. Dispositivos de comunicação móveis. Jovens universitários. 


\section{Introdução}

O número e o uso de dispositivos de comunicação móveis têm crescido significativamente nos últimos anos ${ }^{1}$, ocupando, a cada dia, protagonismos na configuração das interações sociais e proporcionando, consequentemente, a geração de condições propícias para a emergência de processos de midiatização mais abrangentes - pelos quais os meios de comunicação e sua lógica como mídia integram-se em práticas culturais e sociais em vários níveis (HJARVARD, 2014a). Isto ocorre, por exemplo, por meio de ligações, envios de SMSs (Short Message Service), informações e edições em perfis de sites e aplicativos sociais (Facebook, Instagram, YouTube, Twitter, Blogs etc.), mensagens via Instant Messengers (WhatsApp, Facebook Messenger, Snapchat, etc.), dentre diversas outras práticas realizadas por meio de ambientes digitais conectados à internet. 0 uso desses recursos permite a geração de fluxos de informações que podem assumir diferentes formas, lugares, contextos e temporalidades.

A interface entre a mobilidade e a conectividade configura uma complexa rede sociotécnica que engendra particularidades nos modos como as informações são produzidas e compartilhadas entre as pessoas. Em primeiro lugar, há um potencial de permanência das informações compartilhadas entre os usuários, uma vez que podem ser armazenadas nos bancos de dados dos sites e aplicativos, ou mesmo no próprio sistema de memória dos dispositivos. Vale a pena salientar, entretanto, o aparecimento recente de recursos e de aplicativos baseados em permanência reduzida que viabilizam a exposição de informações dentro de um certo período de tempo ${ }^{2}$. Neste sentido, o que parece configurar-se é a presença de diferentes graus de permanência de informações, os quais teriam sua variabilidade de acordo com as características dos aplicativos e dos recursos utilizados. Em segundo lugar, nota-se a buscabilidade (ou resgate) de tais informações ao longo do tempo e em diferentes ambientes digitais. Em terceiro, está o potencial de replicabilidade destas informações (por meio do compartilhamento em outros dispositivos, sites e/ou aplicativos). Por fim, em quarto lugar, há o potencial de escalabilidade das informações produzidas em rede, que podem vir a obter, em alguns casos, alcances globais (BOYD, 2011).

\footnotetext{
${ }^{1}$ Neste artigo, referimo-nos especificamente aos aparelhos de celular com conexão à Internet (smarthphones), sem deixar de reconhecer a diversidade de aparelhos diferentes que podem ser enquadrados na definição de dispositivos móveis de comunicação.

2 No momento da produção deste artigo, o aplicativo Snapchat, os recursos Stories do Facebook e do Instagram, e a função de Status do aplicativo WhatsApp mostram-se com acentuada popularidade entre os usuários brasileiros. Tais recursos permitem o compartilhamento de conteúdos, nos formatos de imagem e video, com permanência de até 24 horas.
} 
Estes aspectos permeiam não apenas o modo como as informações circulam, mas também o modo como as interações são vivenciadas pelos indivíduos - apresentando, consequentemente, desdobramentos nas percepções de presença e de performances realizadas pelos interagentes em contextos de interação. As expressões destas particularidades, comumente associadas aos sites de redes sociais (BOYD, 2011), mostramse potencializadas ao serem vivenciadas por meio da utilização de dispositivos móveis, uma vez que ampliam o leque de configuração de situações interacionais, derivadas da possibilidade de efetivação de acesso, em qualquer momento e em qualquer lugar, a diversos contatos sociais.

Este artigo parte deste cenário de transformações sociotécnicas e realiza um estudo exploratório $^{3}$ sobre como usuários de dispositivos de comunicação móveis percebem a presença de interagentes nas interações mediadas (em especial, no que diz respeito às particularidades associadas à ausência ou diminuição de referências e de pistas não verbais, habitualmente ocorridas nesta modalidade), tendo como comparação as experiências vivenciadas em interações face a face. Para realizar esta análise, utilizamos dados coletados em uma pesquisa qualitativa realizada durante o período de 2015 a 2017. As entrevistas foram realizadas com 120 jovens universitários brasileiros usuários de dispositivos móveis, em seis cidades da região Nordeste do Brasil: Salvador (BA), Cachoeira (BA), Aracaju (SE), Itabaiana (SE), Fortaleza (CE) e Quixadá (CE).

Como base para nossas reflexões analíticas, exploramos os conceitos de Interação e de Presença Social, relacionando-os com as percepções dos respondentes sobre os usos e as apropriações da comunicação móvel na vida cotidiana.

\section{Presença social em interações mediadas por tecnologias da informação e da comunicação (TICS)}

Entendemos a interação social enquanto um conjunto de ações realizadas de forma mútua e interdependente entre indivíduos, ou seja, como "[...] influência recíproca dos indivíduos sobre as ações uns dos outros." (GOFFMAN, 2014, p. 23). Estas ações, entretanto, não se limitam apenas a trocas verbais; seriam formadas, também, por "[...] um complexo fluido e multifacetado de numerosos modos verbais, tonais, posturais, contextuais etc. que,

\footnotetext{
3 De acordo com Creswell (2010), um estudo exploratório tem a finalidade de ampliar a compreensão sobre determinado conceito ou fenômeno, sobretudo quando há a necessidade de explorar e descrever fenômenos, em vistas do desenvolvimento de uma teoria.
} 
em seu conjunto, condicionam o significado de todos os outros" (WATZLAWICK; BEAVIN; JACKSON, 1993, p. 46).

Joseph (2000) sugere que a interação social pode ser identificada a partir de: (1) unidades que interagem entre si; (2) um conjunto de regras que estruturam e orientam as unidades e a própria interação (a exemplo de idiomas, rituais sociais, cultura etc.); (3) um sistema ou um processo ordenado de interação; e (4) um ambiente no qual os componentes apresentam-se e onde há a ocorrência de trocas sistemáticas entre eles. Partindo desta compreensão, observamos que, para que haja fluxos informacionais entre as unidades envolvidas em uma interação, faz-se necessária a percepção da existência de um outro e de sua presença em determinado espaço-tempo que configura o contexto interacional. Estes fluxos de informação (ou trocas simbólicas) entre os indivíduos podem ser observados nas modalidades de interação face a face e mediada.

Para Thompson (2011), a interação face a face é definida como aquela na qual as trocas simbólicas são efetivadas entre indivíduos copresentes em um ambiente físico, assumindo, assim, uma dinâmica dialógica que implica em um fluxo de ida e volta das informações. Estas mesmas informações, por sua vez, seriam trocadas entre os indivíduos a partir de aspectos vinculados a seus corpos, que seriam dotados de múltiplas pistas simbólicas estruturadas e compreendidas socialmente, tais como gestos, posturas, tom de voz, dentre outros elementos não verbais. Estas pistas simbólicas, ainda, conforme argumenta Thompson (2011), permitiriam, ao longo das trocas sociais, a redução de ambiguidades ou de ruídos de interpretação entre os interagentes, uma vez que seria possível ter acesso às reações uns dos outros de formas síncrona e contextualizada.

Por outro lado, historicamente, o desenvolvimento de meios facilitadores para ligações sociais entre indivíduos promoveu a extensão de sentidos, a alteração de processos de consciência, bem como as diversas mudanças de ordens cultural e social. Desde a criação dos papiros, na Roma antiga, passando pelo uso expressivo das cartas e dos telefone fixos, até o estágio vigente em que o uso de recursos eletrônicos consolida-se como meio comunicativo relevante para o desdobramento dos processos em sociedade, a interação entre as pessoas tem exigido cada vez menos a obrigatoriedade da presença física (MEYROWITZ, 1985). A interação mediada, constituída pelo fluxo informacional transmitido entre os interagentes por meio de um aparato técnico (exemplo: uma carta, um telefone fixo, um celular/smartphone, ou mesmo aplicativos de redes sociais digitais e instant messengers), pode apresentar, em maior ou menor grau, uma série de particularidades e 
diferenciações quando comparada com a interação face a face ou com a interação quase mediada (constituída por relacionamentos sociais estabelecidos pelo uso de "mídia de massa", como livros, jornais, rádios). Um exemplo comum diz respeito ao acesso às representações das expressões não verbais que são performadas por meio dos corpos das pessoas envolvidas nas situações sociais (THOMPSON, 2011).

Dentre as particularidades da interação mediada, destacam-se: (a) a extensão das conversações em contextos espaciais e temporais distintos, isto é, os indivíduos não apresentam a obrigatoriedade de estar em um mesmo lugar ou, até mesmo, em uma mesma temporalidade para efetivar uma troca informacional; e (b) a limitação no acesso às expressões não verbais, a depender do meio e do formato de conteúdo selecionado para a troca. A este respeito, Thompson (2011) aponta peculiaridades significativas que sinalizam a complexidade imanente às interações mediadas e propiciam a multiplicidade de expressões sociais potencialmente articuladas aos seus usos. Nesta modalidade comunicacional, usualmente, os indivíduos desenvolvem estratégias interacionais e recursos de linguagem visando o favorecimento e facilitação do intercâmbio comunicacional.

Para observar e compreender as performances cotidianas dos indivíduos e grupos sociais, o sociólogo Erving Goffman desenvolveu uma abordagem microssociológica da interação a partir de metáforas teatrais. Em sua perspectiva dramatúrgica, Goffman (2014) observa os indivíduos enquanto atores que performam para outros (sua plateia), em um determinado espaço social (o palco), a partir de papéis que são gerenciados de forma mútua. Essa performance teria o intuito de gerenciar as impressões pretendidas e manter a coerência expressiva dos atores ao longo da interação, regulando as expectativas que são geradas por ambas as partes (atores e plateia) em uma determinada situação social (GOFFMAN, 2014).

A abordagem dramatúrgica das interações sociais desenvolvida por Goffman teve como foco a interação face a face e, em alguns estudos, chegou a observar casos de interação mediada por telefones fixos. Entretanto, no contexto atual, sua abordagem parece necessitar de complementações, haja vista o papel cada vez mais preponderante das tecnologias digitais nas práticas interacionais. Tendo em vista este cenário, pesquisadores de diferentes campos do saber (THOMPSON, 2011; JACOBSEN, 2010; SCHEFF, 2005; RIBEIRO, 2003; MEYROWITZ, 1985) buscaram estender a abordagem goffmaniana para estudos relacionados às interações mediadas por TICs. 
As particularidades da interação mediada, quando em contraste com as trocas realizadas em presença física imediata ou por interação quase mediada, são identificáveis no que diz respeito às dinâmicas que permitem o encurtamento de distâncias geográficas, a assincronia dos fluxos interacionais, o maior gerenciamento das exposições de si e a reestruturação de práticas sociais (HJARVARD, 2014a). Conforme aponta Hjarvard (2014b), as interações mediadas apresentam transformações amplas e profundas, entre elas: (1) $a$ possibilidade de manter várias interações ao mesmo tempo, ou seja, a possibilidade dos dispositivos multiplicarem as opções disponíveis de interação mediada entre os indivíduos, permitindo que as pessoas possam manter diversas "janelas abertas" em diferentes dispositivos, para interagir com colegas de trabalho, amigos íntimos, realizar transações bancárias, realizar compras etc.; (2) a possibilidade de otimizar a interação social em benefício próprio, ou seja, a possibilidade das pessoas aliviarem o peso das relações sociais, obtendo informações com um menor investimento pessoal; e por fim, (3) a possibilidade de reestruturação das normas sociais, sob a forma de transformações nas normas de comportamento (deferência, tom etc.), demandas e expectativas sociais neste novo contexto.

Percebe-se que, seja em qual modalidade de interação estejamos falando, a percepção da presença dos indivíduos em um determinado contexto constitui um dos pontos-chave para a compreensão das formas como as interações são estabelecidas e mantidas (seja em um ambiente físico ou em um digital). Ao resgatar o conceito de presença, é identificável a existência de uma polissemia no campo acadêmico, uma vez que tal fenômeno tem sido investigado a partir de diferentes abordagens, sejam elas filosóficas, sociológicas, psicológicas ou comunicacionais. Em estudos com foco nas interações sociais mediadas por TICs (IJSSELSTEIJN et al., 2000; RETTIE, 2005; SCHROEDER, 2006; ZHAO; ELESH, 2008), o conceito de presença aparece comumente associado a uma experiência de estar meramente presente em algum lugar ou em alguma situação. Ou seja, um estado psicológico no qual o indivíduo percebe sua existência em um determinado lugar/ambiente (BLASCOVICH, 2002). Já ao tratarem sobre a presença social, os autores referem-se a uma experiência de compartilhamento de presença em um lugar ou em uma situação com alguém.

O termo copresença aparece em alguns estudos com um sentido similar ao de presença social. Para pesquisadores interacionistas clássicos (BLUMER, 1969) , por exemplo, o conceito de copresença descreve uma condição na qual o indivíduo interage com outro face a face, ou seja, com corpos situados em presença física imediata. Contudo, esta noção 
vinculada à presença do corpo, em um ambiente físico, tem sido tensionada nos estudos de interações mediadas, por meio da compreensão da copresença enquanto contexto físico ou simbólico compartilhado entre os indivíduos durante uma interação (RODRIGUES, 2011). Garrison, Anderson e Archer (1999), por exemplo, cunham como presença social virtual a projeção social e emocional dos indivíduos por meio dos meios de comunicação. Tu (2002) utiliza o termo presença social online para denotar o grau de sentimento, percepção e reação de um indivíduo em relação a outro através de um ambiente digital conectado à internet. Tu et al. (2012) trazem a noção de presença social em redes, para avaliar o grau no qual participantes de Redes Sociais Digitais envolvem-se na criação, manutenção e compartilhamento de conteúdo e das suas identidades.

A despeito da pluralidade conceitual associada à percepção de presença dos interagentes nas diversas modalidades interacionais, convém destacar a inseparabilidade dos conceitos, uma vez que a interação social exige, segundo Goffman (2014), o monitoramento dos interagentes, fundamentado em algum nível de percepção de presença, seja ela física, ou seja ela por meio de dispositivos técnicos. Diante deste cenário, repleto de transformações sociotécnicas e de multiplicidade conceitual, é que focamos a nossa discussão sobre como a presença de outros é percebida e comparada em casos de interação mediada e interação face a face, a partir do relato de jovens universitários usuários de dispositivos móveis.

\section{Método}

O recorte proposto neste artigo faz parte de um estudo qualitativo exploratório mais amploque analisou as percepções de jovens universitários sobre os usos e apropriações da comunicação digital móvel, bem como suas possíveis implicações nas práticas interacionais cotidianas. Aqui, apresentamos os dados articulados à especificidade de compreender as dinâmicas de construção de práticas interacionais potencializadas pelos usos de dispositivos de comunicação móveis, nos termos da percepção de presença social a partir das comparações entre interações mediadas por estes dispositivos e interações face a face.

\subsection{Amostra}

A amostra desta pesquisa foi formada por 120 jovens universitários, de seis cidades da região Nordeste do país, sendo três capitais e três cidades do interior, conforme 
ilustração apresentada na Tabela 1.

Tabela 1 - Amostra utilizada para a análise

\begin{tabular}{c|c|c}
\hline Cidade & Universidade & Participantes \\
\hline Salvador/BA & UFBA & 20 \\
\hline Cachoeira/BA & UFRB & 20 \\
\hline Aracaju/SE & UFS e UNIT & 20 \\
\hline Itabaiana/SE & UNIT & 20 \\
\hline Fortaleza/CE & UFC & 20 \\
\hline Quixadá/CE & UFC & 20 \\
\hline & Total & $\mathbf{1 2 0}$ \\
\hline
\end{tabular}

Fonte: Elaborado pelos autores.

Os participantes foram acessados em uma amostragem por conveniência (ou acessibilidade $)^{4}$, a partir das redes de contatos dos pesquisadores. Dos 120 participantes, 61 eram homens e 59 mulheres, com idades variantes entre 18 a 25 anos ( $M=21,26$ anos / Mediana $=23$ anos).

\subsection{Procedimentos de coleta de dados}

Os dados foram coletados por meio de entrevistas estruturadas, com duração situada entre 25 e 35 minutos. As falas dos participantes foram gravadas e posteriormente transcritas para textos em formato digital. Ademais, as sessões de entrevista foram realizadas em ambientes silenciosos, reservados, localizados nas próprias universidades. Antes da aplicação e da gravação de cada entrevista, realizou-se a explicação detalhada dos propósitos da investigação, a solução de eventuais dúvidas e a submissão do participante à assinatura de um Termo de Consentimento Livre e Esclarecido (TCLE).

\subsection{Procedimentos de análise de dados}

Após transcrição digital, as falas geradas pelas entrevistas foram analisadas por meio de análise de conteúdo (BARDIN, 1991), com base em sistemas categóricos

\footnotetext{
4 Amostra por conveniência (ou acessibilidade) corresponde àquela na qual são aproveitados os respondentes imediatamente disponíveis para a participação em uma pesquisa (YIN, 2016).
} 
previamente propostos por Ribeiro (2015), buscando a detecção de aspectos e indicadores qualitativos coerentes aos objetivos da pesquisa. As análises foram realizadas no aplicativo de análise qualitativa de dados ATLAS TI, versão 8, para os sistemas macOS e Windows.

\section{Diferenças entre percepções da presença social em interações mediadas por dispositivos móveis e interações face a face}

Aos serem questionados sobre as diferenças existentes entre a interação mediada por dispositivos móveis e a interação face a face, os respondentes da pesquisa, em maioria, afirmaram perceber particularidades provenientes das interações mediadas. Além disso, foram destacadas algumas consequências, nos processos interacionais, derivadas da percepção da presença social diferenciada nas duas modalidades.

As respostas foram agrupadas em seis categorias, apresentadas na tabela 2, com suas respectivas frequências:

Tabela 2 - Categorias e Frequências

\begin{tabular}{|c|c|c|}
\hline Categoria & Definições & Frequência \\
\hline $\begin{array}{l}\text { Ausência ou diminuição de } \\
\text { referências e de pistas adicionais } \\
\text { oferecidas pela comunicação não } \\
\text { verbal }\end{array}$ & $\begin{array}{l}\text { Ausência ou diminuição de referências } \\
\text { adicionais oferecidas pela comunicação não } \\
\text { verbal associadas a gestos, tons de voz e à } \\
\text { percepção corpórea entre os interagentes. }\end{array}$ & 44 \\
\hline Pessoalidade e impessoalidade & $\begin{array}{l}\text { Percepção de pessoalidade ou impessoalidade } \\
\text { resultante da especificidade do tipo de } \\
\text { interação. }\end{array}$ & 40 \\
\hline $\begin{array}{l}\text { Maior controle das informações } \\
\text { compartilhadas }\end{array}$ & $\begin{array}{c}\text { Gerenciamento efetivo de conteúdos } \\
\text { transmitidos e emitidos nas interações } \\
\text { mediadas. }\end{array}$ & 27 \\
\hline $\begin{array}{l}\text { Diferentes contextos de } \\
\text { enunciação }\end{array}$ & $\begin{array}{l}\text { Questões associadas ao grau de acesso às } \\
\text { particularidades contextuais contingentes aos } \\
\text { interagentes, quando em interações mediadas. }\end{array}$ & 16 \\
\hline $\begin{array}{l}\text { Comunicação em qualquer } \\
\text { momento e em qualquer lugar }\end{array}$ & $\begin{array}{l}\text { Percepção sobre a disponibilidade e a facilidade } \\
\text { dos contatos com interagentes. }\end{array}$ & 3 \\
\hline Outros & $\begin{array}{c}\text { Referências que apresentaram particularidades } \\
\text { não agrupáveis em nenhuma das categorias } \\
\text { anteriores, nem em uma nova categoria. }\end{array}$ & 15 \\
\hline
\end{tabular}

Fonte: Dados da pesquisa.

Os achados apontam a possibilidade de agrupamento das categorias em dois grandes conjuntos. 0 primeiro apresenta as consequências advindas das diferentes modalidades de interação utilizadas pelos indivíduos. Reúne as categorias "Ausência ou diminuição de referências e de pistas adicionais oferecidas pela comunicação não verbal" e "Pessoalidade 
ou impessoalidade", congregando a maior quantidade de referências $(n=84)$. 0 segundo conjunto coleciona as particularidades condicionantes associadas exclusivamente às características das interações mediadas por dispositivos móveis. Congrega as categorias "Maior controle das informações compartilhadas", "Diferentes contextos de enunciação" e "Comunicação em qualquer momento e em qualquer lugar". Diante da pluralidade dos dados agrupados, a categoria "Outros" não foi considerada na formação dos conjuntos categóricos.

As categorias resultantes das análises realizadas neste estudo convergem com os achados em pesquisa similar, realizada por Ribeiro (2015), com estudantes universitários portugueses. Neste artigo, apresentamos a análise de relatos agrupados na primeira categoria, "Ausência ou diminuição de referências e pistas adicionais oferecidas pela comunicação não verbal", como veremos a seguir.

Conforme apresentado na Tabela 2, foram identificadas 44 referências que ressaltaram o tópico da ausência ou diminuição de referências e de pistas adicionais oferecidas pela comunicação não verbal, associadas a gestos, tons de voz e à percepção corpórea entre os interagentes, quando em interação mediada por dispositivos. Com base nas falas dos respondentes, essa foi a principal consequência advinda das diferentes modalidades de interação considerados neste estudo. As falas dos respondentes 15 e 91, respectivamente, exemplificam as particularidades percebidas: "É a questão da conversa, do olho a olho. A questão do seu tom de voz, da forma como você fala. Tem uma diferença gigantesca entre isso e uma comunicação por celular"; "Você consegue perceber os sinais do rosto da pessoa, do tom de voz, do corpo dela. Todos os sinais, a linguagem corporal, que você não tem pelo telefone".

Apesar da aparente avaliação desfavorável mencionada pelos entrevistados, em relação ao uso dos dispositivos móveis na comparação com as interações em copresença física, é importante sinalizar que as particularidades dos distintos tipos de interação pressupõem diferentes estratégias interacionais e de usos dos códigos linguísticos em seus exercícios, o que sugere a existência de dinâmicas diferentes nas naturezas das interações (THOMPSON, 2011). Tal argumento é fundamental para previnir eventuais suposições maniqueístas a respeito dos diferentes tipos de interação que, ao contrário, geralmente coexistem nos processos de sociabilidade (CARON; CARONIA, 2007).

Faz-se adequada a consideração das particularidades técnicas que envolvem os dispositivos e os aplicativos utilizados na comunicação móvel, sobretudo na modalidade escrita. São destacáveis as limitações de acesso dos interagentes à miríade de pistas 
simbólicas articuladas à percepção da presença social, usualmente utilizadas na interação face a face, sobretudo às que dizem respeito aos comportamentos expressivos emitidos por pistas e referências à comunicação não verbal (GOFFMAN, 2014). Todavia, são notáveis, também, os usos de estratégias compensatórias, constituídas para viabilizar a manutenção das coerências expressivas nos processos comunicacionais mediados, bem como de práticas que ampliam o controle sobre as informações pessoais emitidas e sobre os ensaios sociais efetivados por meio dos dispositivos móveis.

Os dados tensionam pontos significativos sobre as diferenças das interações face a face e das mediadas por dispositivos móveis. De início, convidam à reflexão sobre o efeito da inserção das TICs na vida cotidiana que, certamente, afeta não apenas o fluxo de informações entre os indivíduos, mas também a "geografia situacional" da vida social (MEYROWITZ, 1985, p. 6), criando novas situações, novos padrões de fluxos informacionais e ajustamentos de condutas sociais, permeados por uma modalidade comunicacional em profusa expansão na contemporaneidade. Em conformidade com as sugestões de Meyrowitz (1985), é plausível considerar a vigência de uma nova ordem social alicerçada em sistemas informacionais, baseada em fluxos de informação engendrados em espaços com fronteiras cada vez menos claras e com acordos interacionais em constante negociação. A fala do respondente 96 é ilustrativa a esse respeito: "Não existem muitos acordos explícitos, o melhor que se pode dizer é que a melhor hora que você pode usar o celular é a hora que você precisar dele. Mas, implicitamente, ninguém gosta muito do uso excessivo do celular".

Na comparação da interação mediada por dispositivos móveis com a interação face a face, sob o argumento de dificuldades vinculadas à falta de elementos da comunicação não verbal, foi destacada a importância do acesso às tonalidades dos elementos emitidos pelas expressões no desdobramento das interações. Neste sentido, para os respondentes, a impossibilidade de acessarem as extensões de tais elementos dificultaria a compreensão do teor e a interpretação dos conteúdos emitidos nas interações, especialmente, se as estratégias utilizadas para atenuar a ausência das pistas e elementos da comunicação não verbais, a exemplo do uso de Emoticons e Gifs, não fossem realizadas, como ilustra a fala do respondente 1: "Se for utilização de aplicativo de conversa escrita, sim, porque não dá para ver a entonação. Então, às vezes você fala um coisa e a pessoa não entende... e pessoalmente você consegue usar flexões... você consegue ser irônico, você consegue ser engraçado, você consegue ser mais simpático, entendeu?".

Por vezes, a dificuldade no discernimento do teor expressivo colaboraria para o 
desdobramento de conflitos entre os interagentes. As falas a seguir exemplificam tal situação: "Meu namorado fala muito isso. Eu sou muito irônica, mas por brincadeira... E no telefone parece que eu tô sendo irônica por ser chata. Aí ele: tu tá com raiva? Aí eu: não, eu tô brincando! Aí ele: Vala! Tipo assim, teu tom foi muito ruim no telefone! E se ele tivesse comigo, por exemplo, me vendo, ele veria que eu tava brincando. Aí eu acho que tipo, tem interpretação né?" (respondente 3); "Tudo o que você lê, às vezes, você pode interpretar de uma forma errada. Por exemplo: 'Eu já te disse que não vou fazer isso'. A pessoa escreve e você já lê assim: 'Eu já te disse que não vou fazer isso!' Se a pessoa: 'Rapaz, eu não já te falei que eu não vou fazer isso?' fica (não é?) de outro tom. Na mensagem tem isso" (respondente 75); “No virtual a gente não tem aquela... O tom que a pessoa fala, né? Já briguei várias vezes com o meu namorado por não saber o tom que ele estava falando... É bem diferente" (respondente 84).

Adjacente às questões associadas ao decréscimo de captação das tonalidades dos elementos expressivos emitidos, foi recorrente a referência à dificuldade de pareamento do estado afetivo, em termos de humores, dos interagentes em situações de interação mediada por dispositivos móveis, na modalidade escrita, por desconhecimento ou pouca experiência em relação o uso das estratégias compensatórias engendradas nas interações mediadas, conforme observa-se na fala do respondente 5: "Então essa coisa de... olho a olho, face a face, você ver as expressões, você ver o rosto da pessoa, como ela tá, se ela tá gesticulando, se ela num tá, se ela tá nervosa, se ela num tá... você só sabe isso no face a face. Por texto, você você não vai saber, né?".

A respeito dos casos apresentados, é possível inferir que as estratégias utilizadas para compensação da ausência ou diminuição de pistas de comportamentos não verbais, por vezes, são pouco claras aos interagentes, fato que poderia desfavorecer o intercâmbio de gestos socialmente significantes, interferindo, em algumas ocasiões, na percepção de presença social dos interagentes, na comunicação de estados afetivos e nos conseguintes ajustamentos às situações. 0 fato da mediação comunicacional por dispositivos móveis ainda ser uma prática recente, em comparação com outros recursos utilizados na interação face a face, pode estar relacionado com essas incompreensões. Este argumento mostra-se mais plausível, ao se conceber que as apropriações das normas sociais e dos códigos de etiqueta, diretamente associados aos controles expressivos da comunicação social e vinculados aos usos dos recursos articulados aos dispositivos móveis, apresentam-se de forma multifacetada, em razão da multiplicidade de serviços disponíveis e das particularidades de usos pelos distintos grupos sociais. 
Por outro lado, as falas de alguns respondentes enfatizam a preferência pela modalidade de interação mediada em virtude das particularidades associadas aos dispositivos móveis, principalmente, no que se refere ao encurtamento de distâncias geográficas e à possibilidade de assincronia dos fluxos interacionais: "É mais fácil falar com outras pessoas, mesmo que elas não estejam presentes" (respondente 96); "A vantagem é que eu consigo estabelecer contato com várias pessoas ao mesmo tempo, o que eu não conseguiria fazer no cotidiano. Eu consigo me fazer presente mais vezes e com mais constância. Tem amigos mesmo, que eu fico sem ver seis meses, mas a amizade continua a mesma, porque a gente tá se falando, tá se vendo e até quando não fala” (respondente 98).

Um outro aspecto verificado é que a interação mediada por dispositivos móveis, na modalidade escrita, colabora para o uso de certas formas de gerenciamento de informações sobre estados afetivos que nem sempre correspondem aos sentimentos do momento, conforme ilustram as falas a seguir: "Pelo celular, nem sempre isso acontece. Normalmente só tá vendo, tipo... se eu te falar que eu tô triste, mas na verdade eu não tô triste. No celular não dá pra perceber isso" (respondente 25); "Às vezes a pessoa manda um kkkkk... mas não necessariamente ela está rindo" (respondente 26). A este respeito, observa-se como as tecnologias colaboram para a produção de novas práticas de sociabilidade (MEYROWITZ, 1985), uma vez que possibilitam não só desenvolvimento de estratégias comunicacionais compensatórias, mas também o exercício de práticas alternativas de controle e de circulação de informações sociais entre os interagentes envolvidos nas situações interacionais efetivadas.

Em adição, os dados fornecem pontos de reflexões relevantes sobre como o gerenciamento das impressões - em termos de apresentação de si associada a uma condição emocional e do grau de fornecimento de informações sobre esta condição - toma forma nas interações mediadas por TICs. As falas dos respondentes apresentam alguns indicativos que nos ajudam a compreender como as particularidades desse tipo de recurso viabilizam um maior controle sobre as informações pessoais e os ensaios sociais perante as adaptações exigidas durante as interações, a exemplo das falas a seguir: "Você pode deixar a mensagem com a pessoa para ela responder depois... Porque é uma coisa que é fixa, você manda a mensagem a pessoa vai receber" (respondente 1); "Eu acho que você consegue pensar mais antes de enviar" (respondente 11); "Eu acho que, tipo, você tem mais oportunidade de buscar as palavras, entendeu. E quando você tá falando... Já na oralidade, você não consegue, entendeu. Você acaba tendo alguns deslizes, que acaba levando pra outros sentidos" 
(respondente 42).

Ainda em torno das possíveis interferências associadas ao pareamento ou não dos humores e tonalidades expressivas, uma quantidade significativa de respostas destacou a presença de desconforto perante as dificuldades de compreensão dos sentidos associados a algumas figuras de linguagem, conforme podemos verificar na fala do respondente 96: " $E$ mais difícil interpretar, perceber sarcasmo, ironia, esse tipo de figura de linguagem na comunicação por celular ou na comunicação por texto". Ademais, alguns registros enfatizaram a dificuldade em perceber se a performance da pessoa apresentava-se condizente com as expectativas atribuídas à forma costumeira de conduta, como sinaliza a fala do respondente 5: "Saber se a pessoa tá sendo verdadeiro com você, saber se a pessoa... não tá debochando, esse tipo de coisa".

Tais pontos mostram-se relevantes para a configuração das situações sociais, uma vez que circunscrevem a manutenção das fachadas dos atores e o exercício dos acordos interacionais negociados (GOFFMAN, 2010). Desta forma, à medida que os processos de interpretação das pistas emitidas pelos gestos significantes dos indivíduos mostram-se menos compreensíveis, ou pouco pregnantes para seus pares, haverá a tendência a uma menor adaptabilidade às situações sociais (BLUMER, 1969), promovendo, nessa perspectiva, o desenvolvimento de incoerências no processo de interação. Por outro lado, vale ressaltar, mais uma vez, que as dificuldades apontadas pelos respondentes no processo de interpretação dos conteúdos circulados e as eventuais incoerências derivadas podem criar situações propícias ao desenvolvimento de formas alternativas de estratégias comunicacionais, tais como a priorização do uso assíncrono do fluxo comunicacional e o maior controle em termos de compreensão e produção de posteriores respostas. As falas dos respondentes 1 e 14, respectivamente, são exemplares neste sentido: "Você pode deixar a mensagem com a pessoa para ela responder depois... Porque é uma coisa que é fixa, você manda a mensagem a pessoa vai receber"; "Normalmente é quando [...] você não quer justamente repassar pro outro o seu estado atual [...] Às vezes quando você quer esclarecer tipo, melhor em tópicos as coisas, quando você quer deixar as coisas mais claras".

Outro aspecto de bastante relevância na fala dos respondentes relacionou-se com a dificuldade de adaptação diante da pouca informação a respeito das reações dos indivíduos, provenientes da interação mediada na modalidade escrita. As falas, em geral, sugerem que as interações seriam melhor compreendidas na modalidade face a face, conforme exemplificado pela fala do respondente 25: "Você meio que consegue interagir melhor com a 
pessoa porque você tá vendo ela, tá vendo tipo as feições dela. Você sabe exatamente, tipo, a reação dela quando você fala alguma coisa".

No que tange à mediação por dispositivos móveis pela modalidade de voz, observouse a diminuição das incoerências interpretativas quanto ao teor do conteúdo, conforme sinaliza o respondente 54: “Voz, não, porque a voz dá pra sentir, mais ou menos o tom, dá pra ter mais ideia". A preferência pelas interações na modalidade de voz nas interações mediadas é coerente com as sinalizações da Media Richness Theory (MRT) (DAFT; LENGEL; TREVINO, 1987). Tal teoria sugere que a progressão da riqueza comunicacional está relacionada com a multiplicidade de pistas comunicativas, o maior potencial de feedback imediato, a habilidade em se comunicar por meio da utilização de linguagem habitual e a pessoalidade, elementos que viabilizariam maior potencial de presença social nas modalidades de comunicação por voz em comparação com as modalidades escritas.

Por fim, um último aspecto a ser ressaltado quanto à percepção da presença social, relaciona-se à abertura ou não dos interagentes para o ingresso ou para a manutenção da interação social mediada por dispositivos móveis ser condicionada à modalidade adotada (escrita ou por voz) para tal. A fala do respondente 12 é reveladora neste sentido: "Se for um áudio, é muito chato de ouvir". Para além da mera dificuldade de compreensão dos conteúdos circulados, apontada anteriormente, o que parece evidenciar -se, aqui, é que a preferência por uma modalidade em relação a outra (no caso, pela escrita em relação à voz) mostra-se associada à presença de outros fatores condicionantes, tais como, o tipo de vínculo construído entre os interagentes ("Eu prefiro digitar e usar a modalidade escrita com pessoas que eu convivo diariamente, mas por exemplo, pra ligar pra meus pais, eu prefiro ouvir a voz deles do que digitar mensagem" - respondente 45), as expectativas sociais derivadas das particularidades dos contextos em que se encontram ("Eu prefiro muito por mensagem de voz, mas como em alguns momentos você não tem como tá falando ali; pra enviar, aí eu escrevo, olho, olho de novo o que eu tô escrevendo pra não ficar nenhuma dúvida"respondente 57), dentre outros.

\section{Conclusão}

Este artigo apresentou uma análise proveniente de um estudo exploratório sobre diferenças na percepção da presença social por jovens universitários usuários de dispositivos móveis em comparação com as interações do tipo face a face. Esta análise faz parte de uma pesquisa mais ampla que investigou não só as expectativas e os significados 
construídos por esses jovens nos usos e nas apropriações da comunicação digital móvel, bem como sobre suas possíveis implicações nas práticas interacionais cotidianas.

Os dados da pesquisa demonstraram similaridades com achados em pesquisa anterior, realizada por Ribeiro (2015), com jovens universitários portugueses, residentes na cidade de Lisboa, em Portugal. Em ambas as pesquisas, foram identificadas e confirmadas seis categorias relacionadas ao tema da percepção da presença.

Para este artigo, selecionamos para análise a categoria Ausência ou diminuição de referências e pistas adicionais oferecidas pela comunicação não verbal que se mostrou bastante relevante nos relatos dos jovens colaboradores.

Destacou-se a preponderância de respostas que ressaltaram dificuldades na vivência da presença social, devido à sobreposição de demandas e expectativas sociais derivadas tanto dos contatos efetivados na modalidade mediada por dispositivos móveis, quanto daqueles decorrentes da modalidade face a face. Dessa maneira, propiciou-se, por um lado, eventuais ocorrências de impropriedades situacionais, em formas de linhas de comportamentos incoerentes e, por outro, o desenvolvimento de estratégias comunicacionais compensatórias e de novos arranjos e acordos de conduta social.

Este resultado é coerente com a sugestão de que a adoção de novas tecnologias não suplanta outras formas de sociabilidade e de comunicação interpessoal, mas produz novas formas de se relacionar (CARON; CARONIA, 2007; MEYROWITZ, 1985). Isto mostra-se claro na medida em que as interações face a face, mediadas diretamente pelas propriedades sensoriais do corpo, articulam-se com outras formas de modalidades interacionais, enriquecendo os processos de comunicação social, sob a lógica de novos padrões de sincronização no espaço e no tempo, gerando novos referenciais para os acordos sociais.

A preponderância do referencial das comunicações face a face pelos respondentes mostra-se coerente, visto que constitui o meio de interação social mais usual desde os processos primários de socialização dos indivíduos (BERGER; LUCKMAN, 2014). Todavia, é fundamental considerar que as estratégias utilizadas nas interações mediadas são compostas por condicionantes e estratégias peculiares que viabilizam a manutenção dos fluxos comunicacionais, o que aponta a incoerência da discussão maniqueísta sobre eventuais melhores ou piores tipos de comunicação. Ressalta-se, ainda, que, diante da substantiva popularização e rotinização do uso de dispositivos móveis conectados à internet, é justificável a expectativa de que as diferenças da percepção de presença social entre ambas modalidades interacionais tendam a se reconfigurar ao longo do tempo. 
Contudo, ainda sob a lógica das sugestões de Meyrowitz (1985), é conveniente considerar que o incremento de TICs cria condições propícias para a emergência de dinâmicas sociais complexas, compostas de rupturas e de continuidades nos padrões de ordenamento social. Isto nos convida à reflexão sobre como as diferentes formas de sociabilidade, ancoradas por comunicações mediadas, por comunicações face a face e por comunicações quase mediadas, relacionam-se para o desenvolvimento de acordos interacionais na atualidade. É problematizável, pois, a coerência na divisão analítica em termos de "ou - ou" para as diferentes modalidades de comunicação, tendo em vista que a proliferação dos dispositivos móveis colabora para a manutenção de interações em espaços híbridos e complementares (CARON; CARONIA, 2007).

A discussão fomentada pelos dados fornece-nos um complexo panorama atual a respeito dos condicionantes que fundamentam as trocas sociais. Convida-nos, assim, ao vislumbre do desenvolvimento de recursos metodológicos, analíticos e teóricos que permitam maiores entendimentos sobre as dinâmicas associadas às variáveis intersecionadas pelas modalidades de copresença física e mediada nos processos interacionais vigentes.

Por fim, é necessário considerar limitações provenientes da análise das falas dos respondentes. É notável que as comunicações mediadas por dispositivos móveis realizam-se tanto por meio da oralidade - por meio de ligações e mesmo vídeoconferências -, como por meio de mensagens de texto ou compartilhamento de imagens. Por vezes, as particularidades do tipo de recurso comunicativo apresentam-se indiferenciadas nas falas dos respondentes. Ressaltam-se, também, as limitações em clarificar se as particularidades associadas ao uso de voz diziam respeito às ligações ou às ações mediadas por aplicativos, elementos que permitiriam enxergar de formas mais robustas as influências de suas particularidades nas dinâmicas interacionais.

\section{Financiamento}

Pesquisa desenvolvida com o apoio do Conselho Nacional de Desenvolvimento Científico e Tecnológico (CNPq), Edital Universal CNPq n. 14/2014, Processo 449466/20144. 


\section{Referências}

BARDIN, L. Análise de conteúdo. Lisboa: Edições 70, 1991.

BLASCOVICH, J. Social influence within immersive virtual environments. In: SCHROEDER, R. (Ed.). The social life of avatars: presence and interaction in shared virtual environments. London: Springer, 2002. p. 127-145.

BERGER, P. L; LUCKMAN, T. A construção social da realidade. Petrópolis: Vozes, 2014.

BLUMER, H. Symbolic interactionism: perspective and method. Los Angeles: University of California Press, 1969.

BOYD, D. Social Network sites as networked publics: affordances, dynamics, and implications. In: Papacharissi, Z. (Ed.). A networked self: identity, community and culture on social network sites. New York: Routledge, 2011. p. 39-58.

CARON, A. H.; CARONIA, L. Moving cultures: mobile communication in everyday life. Québec: McGill-Queen's University Press, 2007.

CRESWELL, J. W. Projeto de pesquisa: métodos qualitativo, quantitativo e misto. 3. ed. Porto Alegre: Artmed, 2010.

DAFT, R. L.; LENGEL, R. H.; TREVINO, L. K. The relationship among message equivocality, media selection, and manager performance. MIS Quarterly, Minneapolis, v. 11, n. 3, p. 355366, 1987.

GARRISON, D. R.; ANDERSON, T.; ARCHER, W. Critical inquiry in a text-based environment: computer conferencing in higher education. The Internet and Higher Education, $\mathrm{New}$ York, v. 2, n. 2-3, p. 87-105, 1999.

GOFFMAN, E. Comportamento em lugares públicos: notas sobre a organização social dos ajuntamentos. Petrópolis: Vozes, 2010.

GOFFMAN, E. A representação do eu na vida cotidiana. Petrópolis: Vozes, 2014.

HJARVARD, S. Midiatização: conceituando a mudança social e cultural. Matrizes, São Paulo, v. 8, n. 1, p. 21-44, 2014a.

HJARVARD, S. A midiatização da cultura e da sociedade. São Leopoldo: Editora Unisinos, 2014b.

IJSSELSTEIJN, W. A. et al. Presence: concept, determinants and measurement. In: SPIE CONFERENCE, 5., 2000, San Jose. Proceedings... San Jose: SPIE, 2000. p. 520-529

JACOBSEN, M. H. (Org). The contemporary Goffman. Londres: Routledge, 2010.

JOSEPH, I. Erving Goffman e a microssociologia. Rio de Janeiro: Fundação Getúlio Vargas, 2000. 
MEYROWITZ, J. No sense of place. New York: Oxford, 1985.

RETTIE, R. M. Presence and embodiment in mobile phone communication. PsychNology Journal, Padova, v. 3, n. 1, p. 16-34, 2005.

RIBEIRO, J. C. Percepções sobre usos e apropriações de dispositivos comunicacionais móveis nas práticas interacionais contemporâneas: um estudo com jovens universitários portugueses. Lisboa: Universidade Nova de Lisboa, 2015. Relatório de Pesquisa de Pós-Doutorado.

RIBEIRO, J. C. Um olhar sobre a sociabilidade no ciberespaço: aspectos sociocomunicativos dos contatos interpessoais efetivados em uma plataforma on-line. 2003. Tese (Doutorado em Comunicação) - Programa de Pós-Graduação em Comunicação e Cultura Contemporâneas, Universidade Federal da Bahia, Salvador, 2003.

RODRIGUES, A. D. 0 paradigma comunicacional: histórias e teorias. Lisboa: Fundação Calouste Gulbekian, 2011.

SCHEFF, T. Goffman unbound: a new paradigm. New York: Paradigm Publishers, 2005.

SCHROEDER, R. Being there and the future of connected presence. Presence: teleoperators and virtual environments, Cambridge, v. 15, n. 4, p. 438-454, 2006.

THOMPSON, J. B. A mídia e a modernidade: uma teoria social da mídia. 12. ed. Petrópolis: Vozes, 2011.

TU, C. H., The measurement of social presence in an online learning environment. Interntional Journal on E-Learning, Waynesville, v. 1, n. 2, p. 34-45, 2002.

TU, C. H. et al. A study of the predictive relationship between online social presence and online interaction. International Journal of Distance Education Technologies,

Athabasca, v. 10, n. 3, p. 53-66, 2012.

WATZLAWICK, P.; BEAVIN, J. H.; JACKSON, D. D. Pragmática da comunicação humana: um estudo dos padrões, patologias e paradoxos da interação. 9. ed. São Paulo: Cultrix, 1993.

YIN, R. Q. Pesquisa qualitativa: do início ao fim. Porto Alegre: Penso, 2016.

ZHAO, S.; ELESH, D. Copresence as 'being with'. Information Communication and Society, Oxon, v. 11, n. 4, p. 565-583, 2008. 


\title{
Perceptions of social presence in interactions mediated by mobile communication devices
}

\begin{abstract}
This article presents a qualitative analysis about the perception of Social Presence in interactions mediated by mobile devices, focusing on the particularities associated with the absence or the decrease of non-verbal clues (which usually occur in this modality). The data came from a survey conducted with 120 young university students from six Brazilian cities. In general, the narratives showed difficulties in the perception of social presence due to the overlapping of demands and social expectations derived from the two interactional modalities: mobile devices and face to face encounters.
\end{abstract}

\section{Keywords}

Social presence. Social interactions. Mediated interactions. Mobile communication devices. Young university students.

Recebido em 16/10/2017

Aceito em 03/12/2017 